\title{
TO COMPARE THE SENSITIVITY OF URINARY POLYMERASE CHAIN REACTION (PCR) WITH INTRAVENOUS UROGRAPHY (IVU) AND URINE ACID FAST BACILLI IN A CLINICALLY SUSPECTED CASE OF GENITO URINARY TUBERCULOSIS (GUTB)
}

\author{
Sudha Karan Selvaraj ${ }^{1}$
}

${ }^{1}$ Assistant Professor, Department of Urology, Government Chengalpattu Medical College, Chengalpattu, Tamilnadu, India.

\section{ABSTRACT}

\section{BACKGROUND}

Tuberculosis is as old as human race. Introduction of Anti-tuberculosis drugs has reduced death due to this disease. About $30 \%$ of extra pulmonary TB involves uro-genital tract. Mostly sexually active age group (20-40 years) with male preponderance is observed. Most sensitive investigations for UGTB are compared in this study.

\section{MATERIALS AND METHODS}

Patients with irritative lower urinary tract symptoms due to GUTB are studied prospectively for a period of 1 year.

\section{RESULTS}

The results of comparison of the three investigations in detecting GUTB are

1. The sensitivity of urinary PCR varied between $75-80 \%$

2. The sensitivity of urinary AFB- $50-55 \%$

3. The sensitivity of urinary IVU $50 \%$

\section{CONCLUSION}

Of the three investigations compared urinary PCR, Urine for AFB and IVU, Urine PCR for AFB is the most sensitive indicator in diagnosing GUTB.

\section{KEY WORDS}

GUTB, PCR, IVU, AFB.

HOW TO CITE THIS ARTICLE: Selvaraj SK. To compare the sensitivity of urinary polymerase chain reaction (PCR) with intravenous urography (IVU) and urine acid fast bacilli in a clinically suspected case of genito urinary tuberculosis (GUTB).J. Evolution Med. Dent. Sci. 2018;7(49):5308-5322, DOI: 10.14260/jemds/2018/1176

\section{BACKGROUND}

Tuberculosis is as old as human race. It is called as consumption disease during $19^{\text {th }}$ century as it was a major killer. Introduction of anti-tuberculosis drugs has greatly reduced incidence of death and new cases but still tuberculosis is a large public health problem. People living in crowded areas with poor nutrition, poverty are at risk. The development of resistant strains is a major obstacle. Its association with HIV leading to acquired immune deficiency syndrome (AIDS) is another worrying problem. 10 to $15 \%$ of people infected with TB are prone to develop genitourinary tuberculosis. About $30 \%$ of the extra pulmonary TB involves the uro-genital tract and roughly about $5 \%$ of all cases of TB is GUTB. Evaluation of PCR for the diagnosis of tuberculosis. (2) GUTB is a disease of male preponderance. The sexually active periods 20-40 Years is the most affected age groups. GUTB usually manifest about 15-20 years after initial pulmonary infection. 70\% of AIDS patients have extra pulmonary lesions.

'Financial or Other Competing Interest': None.

Submission 29-08-2018, Peer Review 17-11-2018,

Acceptance 22-11-2018, Published 03-12-2018.

Corresponding Author:

Dr. Sudha Karan Selvaraj,

No. 1, Meeyanna Kadin Street,

Vandavasi-604408, Tamilnadu, India.

E-mail:tarugiffy@gmail.com

DOI: $10.14260 /$ jemds $/ 2018 / 1176$

(c) $(1) \ominus$

\author{
MATERIALS AND METHODS \\ Study Group \\ Patients admitted in Chengalpattu Medical College, with \\ irritative lower urinary tract symptoms due to GUTB.
}

Study Design- Prospective clinical study.

Study Period- 1 Year.

\section{Inclusion Criteria}

Patient with complaints of-
a. Irritative Voiding Symptoms.
b. Sterile pyuria.
c. Hematuria.
d. Constitutional Symptoms.
e. Low grade fever.
f. Loss of Appetite/weight.
g. Flank pain.
h. Scrotal sinus/Swelling.

\section{Exclusion Criteria}

Other causes of sterile pyuria, irritative lower urinary tract symptoms hematuria is ruled out.

Clinical presentations of GUTB/irritative voiding symptoms
1. Urgency.
2. Dysuria.
3. Increased frequency.
4. Rarely urge incontinence.
5. Nocturia. 


\section{Hematuria}

- $10 \%$ macroscopic.

- $50 \%$ microscopic.

\section{Flank Pain}

- Dull aching, dragging type.

- Due to Hydronephrosis, stretching of renal capsule.

\section{Constitutional Symptoms}

Chronic low-grade fever, night sweats, loss of weight, loss of appetite, malaise, lassitude.

\section{Rec. UTI}

Recurrent or resistant UTI, negative culture for any normal bacterial infection. Renal calcification in genito-urinary tuberculosis. ${ }^{(3)}$

\section{Scrotal Mass}

Painless hydrocele- secondary, epididymal thickening, tender cord structures.

\section{Fistulae}

May be seen in renal TB with communication to GIT, skin, retro peritoneum. Fistula can also be seen in relation to testis and epididymis. Usually the sinus is seen in posterior aspect of scrotum, of chronic duration with discharge and undermined edges.

\section{Infertility}

Mostly in females with features of tubal block, involvement of ovaries, endometrium. In male, apart from kidney, prostate and seminal vesicle are involved.

Renal failure/renal failure is a late feature, involving one kidney followed by another. All patients were subjected to-

1. Urine routine examination.

2. Urine culture and sensitivity.

3. Complete haemogram.

4. Renal function test, 5 USG.

\section{In addition}

1. Urine acid-fast bacilli.

2. Urinary PCR for acid fast bacilli.

3. Intra-venous urogram were done.

\section{Urine for AFB}

Either multiple early morning sample (2 to 3 ) or consecutive 24 hours urine sample collected. The collected urine mixed well and $50 \mathrm{ml}$ of urine is taken in a test tube and centrifuged at $3000 \mathrm{rpm}$ for $30 \mathrm{~min}$. Supernatant is discarded, sediment placed on a slide and stained using Ziehl-Neelson stain. The positivity rate of urine AFB is $41 \%$ single sample, for multiple samples, it ranges from 40 to $60 \%$.

\section{Intravenous Urogram}

After confirming the renal function is normal patient is planned for IVU. The dose of low osmolar, nontoxic contrast media at rate of $1 \mathrm{mg} / \mathrm{kg}$ body weight is calculated and given as IV bolus. serial pictures taken 3, 5, 15, 45 minutes. Post- voidal, 6 hours delayed, and prone pictures also taken in circumstances.

\section{Findings in IVU include-}

1. Kidneys-dilated calyx, infundibular stenosis, hydronephrosis, Nonfunctional kidney.

2. Ureter- single or multiple ureteric stricture.

3. Bladder- small capacity or Thimble bladder.

\section{Earliest changes in GUTB-}

1. Loss of sharpness or blunting of calyx.

2. Moth eaten appearance or erosion of calyx.

3. Infundibular stenosis.

4. Phantom calyx.

5. Renal cavitation.

6. Pseudo tumor Pseudo calculi.

7. Renal scar.

8. Nonfunctioning kidney.

\section{Urine-PCR for AFB}

Entire first morning sample of urine collected, centrifuged at $3000 \mathrm{rpm}$ for 30 minutes. The resultant divided into 3 portions in $20 \mathrm{~mm}$ tris. DNA extraction is done in sterile condition using laminar flow. DNA is added to reaction. Mixture. Post amplification identification was done for MPB64 gene of MTB complex. DNA was extracted with proteinase- $\mathrm{K}(1 \mathrm{mg} / \mathrm{ml})$ and $0.5 \%$ tween 20 followed with phenol or chloroform and again precipitated with ethanol. Management of non-pulmonary forms of tuberculosis. $(4)$

\section{Confirmation}

Done using southern blot and hybridization technique. If 241 $\mathrm{Bp}$ is positive on agar gel the urinary PCR reaction is considered positive.

\section{If absent test, considered negative- \\ - $\quad$ Sensitivity- $97 \%$ \\ - $\quad$ Specificity- $76 \%$.}

Urinary PCR useful in paucibacillary conditions. It gives a faster and specific result. It can detect 1 bacterium to about 10 organisms. Urinary PCR is specific for MTB complex- M tuberculosis, $\mathrm{M}$ bovis. False Negative range from $5 \%$. There is no cross reaction.

\section{False negativity is due to-}

1. Presence of Inhibitors.

2. Unequal distribution of bacteria.

3. False positivity is due to presence of amplicons, dead bacteria.

\section{Pathology}

Tuberculosis is an important public health problem the WHO estimates new TB cases accounts for about 34\% in south eastern Asia region when compared globally.

Timely diagnosis and treatment will prevent complications with GUTB being second most form of extra pulmonary tuberculosis. Kidney is primary organ involved, having varied presentation-mostly irritative voiding symptoms. The frequency of organ involvement is kidney, bladder, tubes and scrotum. 


\section{Parenchymal Change}

Initially medulla of renal parenchyma is spared. The upper and lower poles of kidney are most common site. The cortical granuloma enlarged and join leading to bacillary spilling down the nephron.

These bacteria are trapped in the narrow segment of Henle's loop, acting as new foci of infection within renal pyramid. This papillary lesions cavitate, caseate and forms ulcerocavernous lesions and erode into pelvicalyceal system.

The most common site for stricture formation is calyceal neck, pelvi-ureteric junction, ureterovesical junction. Early scarring is reversible.

GUTB of kidney is a competitive process between destructive effects of bacilli, obstruction of urinary tract, host defense mechanism and the healing mechanism leading to-

1. Granulomas,

2. Calcifications,

3. Fibrosis,

4. Stricture formation.

All these leads to nonfunctioning, calcified kidney known as autonephrectomy.

\section{Tuberculous Interstitial Nephritis (TIN)}

TB of kidney may also occur insidiously called TIN. If untreated leads to renal failure. These bacilli if opens into interstitium may lead to isolated interstitial disease. They will not have sterile pyuria, hematuria, demonstration of AFB in urine which leads to a diagnostic problem. Histology shows chronic TIN which may or may not be associated with granuloma or caseation with proper staining with AFB can be demonstrated on histology. These patients may have reduced glomerular filtration rate, if diagnosed early can overcome by giving ATT and steroids. There are also reports that TIN can occur as a complication of intra vesical administration of BCG.

\section{Renal Failure}

Incidence of renal failure in GUTB varies between $20-24 \%$, various mechanism involved are-

1. Obstruction of urinary tract due to multiple strictures.

2. Dystrophic calcification, renal amyloidosis.

3. Renal parenchymal infection causing obliterative end arteritis.

\section{Complications \\ Extra Renal Spread}

GUTB spread to perinephric and paranephric, retro peritoneal with fistula formation involving the gastro intestinal tract, skin, lymph vessels, pleura, bronchus. There are reports of liver abscess in GUTB.

\section{Amyloidosis}

A complication of chronic TB, leading on to end stage renal disease in patients not treated early.

\section{Squamous Metaplasia}

A risk factor for development of squamous cell carcinoma, which is a complication of infection of 6 renal pelvis and chronic inflammation.

\section{Imaging Studies/ Intravenous Urography}

GUTB mostly spreads through hematogenous route. Only 1012 cases show positive chest x-ray for TB. Extra pulmonary disease process includes calcification of lymph nodes, prostate, vas deferens, adrenal gland, psoas abscess. Calcification in GUTB in plain x rays is $20-40 \%$ which is one of the first sign in many cases. These fine calcifications are best visualized in plain CT.

Focal globular calcification is feature of renal papillary necrosis. Calcified caseous tissue appearing less dense, homogenous resembling ground glass is called putty kidney. It is called putty like kidney if the calcification is more than $1 \mathrm{~cm}$.

The pathognomonic feature of renal TB is lobar calcification with peripheral rim of calcification, a feature of advanced renal TB. The presence of hydrocalycosis pushes the normal renal parenchyma to the periphery causing calcification to appear as lobar rim.

These calcifications may also involve ureter. The occurrence of upper ureter calcification along with renal calcifications, good evidence of renal TB. There may be soft tissue calcification during the process of healing associated renal TB, these calcifications are shapeless and called as scarred calculi they do not form the shape of renal pelvis.

IVU gives both anatomical and functional details of kidney. In about $10-15 \%$ of patients IVU may be normal in GUTB patients. The earliest changes of GUTB in IVU are seen in minor calyces which may appear as minimal calyceal dilation and there may be loss of sharpness of calyces due to mucosal edema.

As the disease advances, calyx may appear irregular, ragged, fuzzy and moth-eaten. There are reports that papillary necrosis may be the first sign due to erosion of papilla in TB, there may be caseating tuberculoma in the renal parenchyma which ruptures into calyx.

\section{Types of Papillary Necrosis}

1. Central type.

2. Forniceal type.

TB papillary necrosis result from direct tissue destruction which is feature of forniceal type. The central type may be due to ischemia and TB endarteritis. There may be communication through the medullary cavity into collecting system also irregular pools of contrast within the calyces.

\section{Advanced GUTB shows-}

1. Scar,

2. Fistula formation,

3. Cavities,

4. Strictures,

5. Mass lesions,

6. Perinephric abscess,

7. Autonephrectomy.

8. Calcification,

\section{Cavitation}

Due to fibrotic deformity of calyx, tips of minor calyx are clubbed as a result they are filled with necrotic material. Types:

1. Obstructive.

2. Non-Obstructive. 
In obstructive type, contrast material does not enter cavity due to stenosis seen in RGP. Whereas in non-obstructive type opacification of calyx is seen only in RGP. The obstructive type should be monitored with serial USG.

The enlarging tuberculoma leads to parenchymal cavities. Those kidneys with cavitations are called ulcerocavernous kidney. These do not excrete contrast material; these cavities open into collecting system leading to TB bacilluria thereby disease spreading to other parts of urothelium.

\section{Stricture/ Scar}

The renal damage due to stricture is far greater than renal tuberculoma the three most common areas of fibrosis in GUTB are-

1. Lower ureter.

2. PUJ.

3. Infundibulum.

4. Rarely.

5. Calyceal neck.

6. Infundibulum.

7. Renal pelvis.

\section{Mass Lesion}

In late stages of GUTB the disease may present as either hydronephrosis or TB granuloma.

\section{Calcification}

The characteristic pattern is lobar calcification. There may be pseudo calculi formation. In IVU, ureter may show-

1. Multiple stricture.

2. Single stricture with other findings.

3. Autonephrectomy.

\section{Autonephrectomy}

In advance stage GUTB, granulomatous destruction of renal parenchyma progress to autonephrectomy along with obstructive uropathy.

\section{Types}

1. Caseocavernous.

2. Shrunken, fibrotic.

\section{Both types are nonfunctional}

Nonfunctioning kidneys in GUTB may be due to-

1. Autonephrectomy.

2. Obstruction- ureteric obstruction, fibrosis.

3. Reno vascular hypertension- renal artery stenosis.

\section{The Various other complications of Renal TB are-}

1. Fistulae.

2. Malignancy.

3. Peri Nephric abscess.

4. Perinephritis.

5. Renal failure.

6. Psoas abscess.

\section{Bladder and Urethral Tuberculosis}

The incidence of bladder TB in GUTB is one third, the lesion starts as mucosal tubercle which joins to form multiple superficial ulcers. The features of this ulcer are-
1. Shallow.

2. Irregular.

3. Undermined edges.

Patient may present with Ureteral Obstruction if there is Oedema of Trigone Mucosa-

IVU in Bladder TB shows following features-

1. Small capacity bladder.

2. Irregular adhesive band.

3. Ulcers- filling defects.

4. Diffuse wall thickening.

5. Solid mass like lesion.

The infection in bladder also involves muscular layer which leads to mural fibrosis as a result the bladder is contracted and thickened. The trigone may be fibrosed which produces a gaping ureteric orifice which leads to VU reflux.

\section{Urethral Tuberculosis}

Tuberculosis of male urethra is uncommon. It is usually due to secondary infection of prostate or kidney. Patient present with nonspecific stricture. The most common site being bulbomembranous urethra.

\section{Patients may also present with-}

1. Peri urethral abscess.

2. Multiple fistula of the urethra.

3. Water-can perineum.

\section{Prostatic and Genital Tuberculosis}

The incidence of male Genital TB is t $30-90 \%$ in GUTB. IT is most commonly seen in age of $20-40$ years, sexually active period. The various presentation of male genital TB includes-

1. Pain over testicles.

2. Painless enlargement of scrotum.

3. Sinus opening in the posterior scrotum.

4. Enlarged epididymis.

The Various other Sites that may be involved are

1. Vas deferens.

2. Prostate.

3. Seminal vesicle.

4. Rarely penis.

In Women, most Common Presentation of Genital TB is Infertility. The Various routes of Infection are-

1. Direct extension from intestinal source.

2. Hematogenous.

3. Lymphatic spread.

4. Peritoneal implants.

The Fallopian Tubes are Most Commonly Involved. They may Present as calcification in

1. Multiple strictures.

2. Pyosalpinx.

3. Hydrosalpinx. 


\section{Analysis of Study}

\section{1) Sex Distribution}

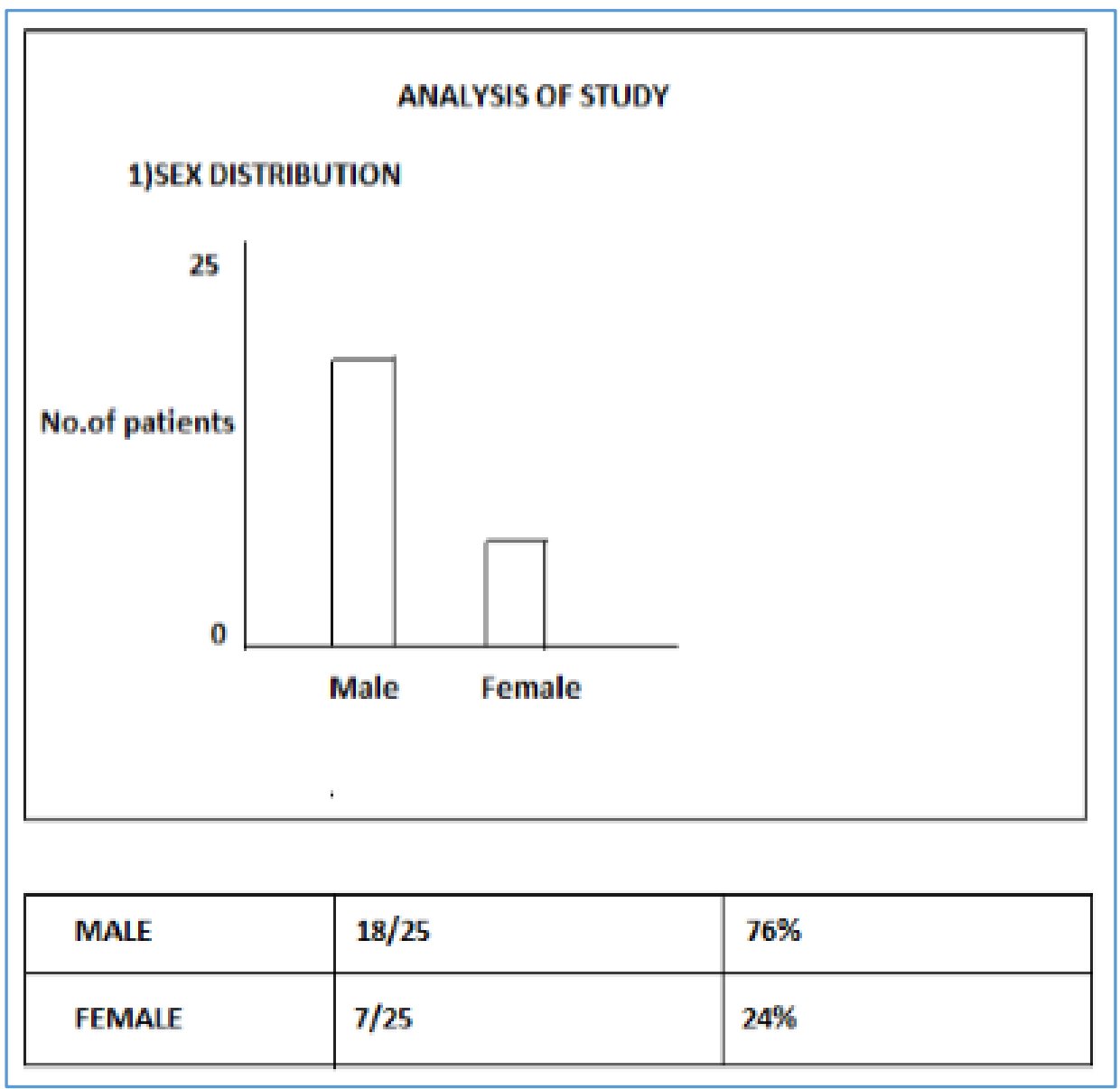

$76 \%$ of patients in study group were males, remaining females.

\section{Age Distribution}

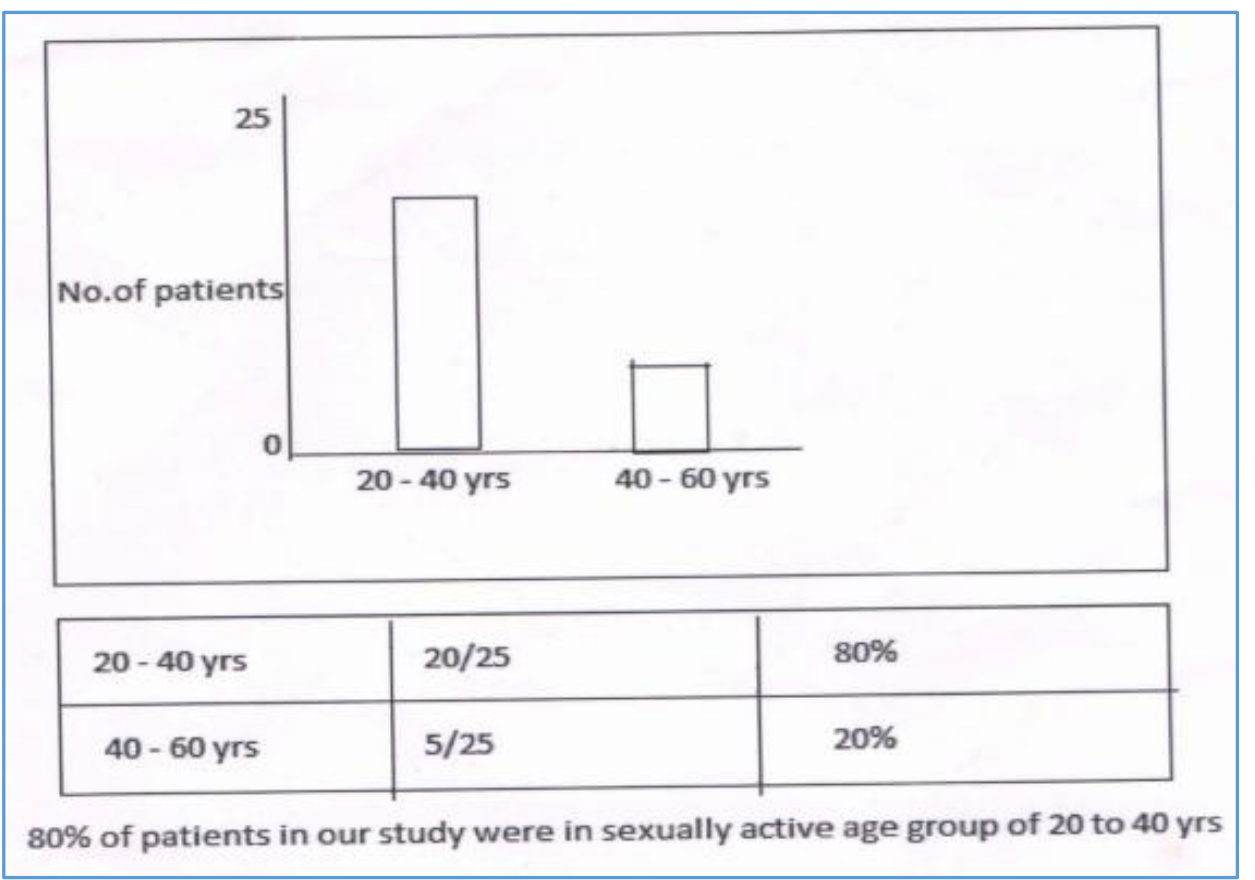




\section{H/O Contact with PT}

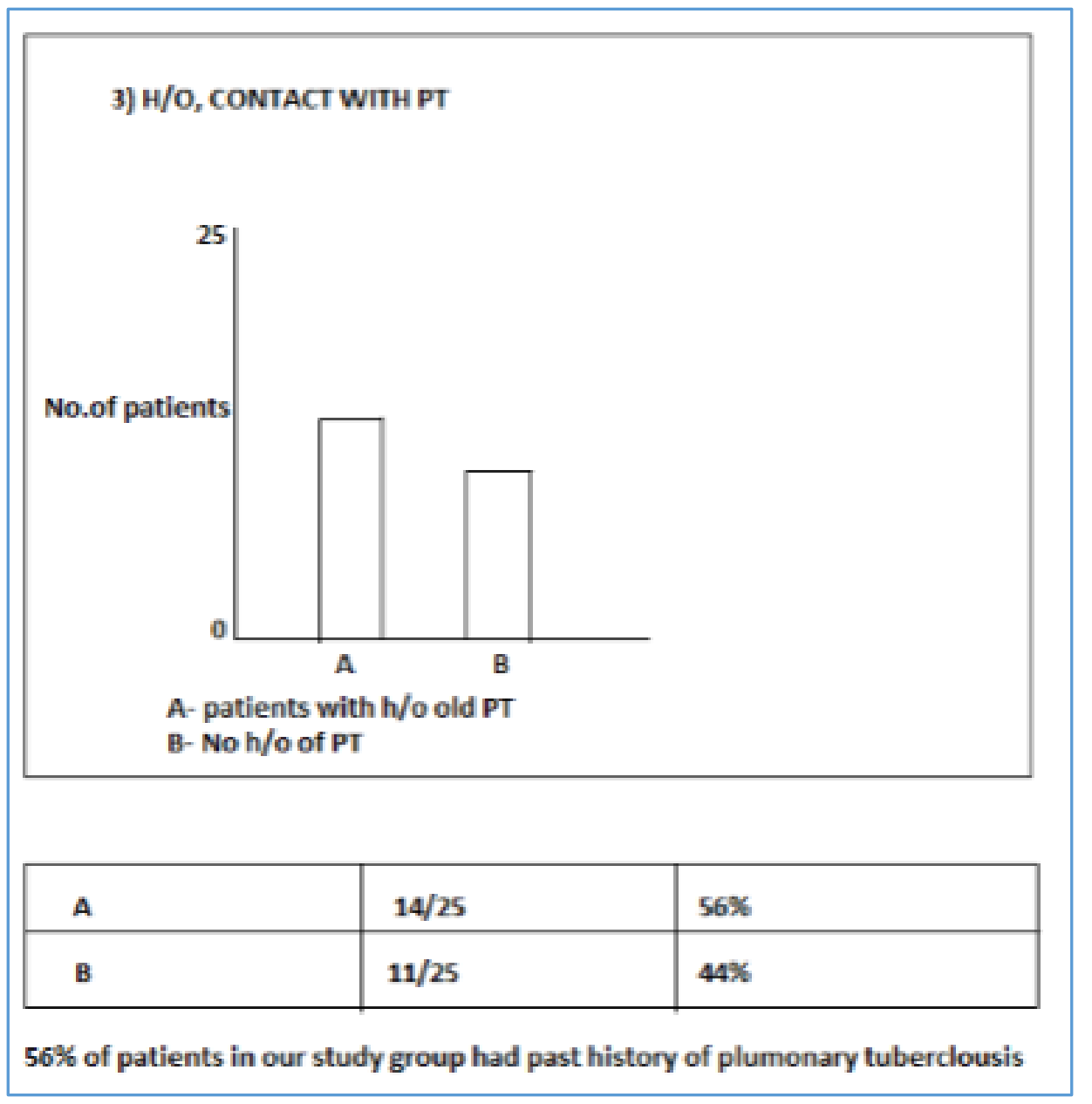

4. Compliance of ATT

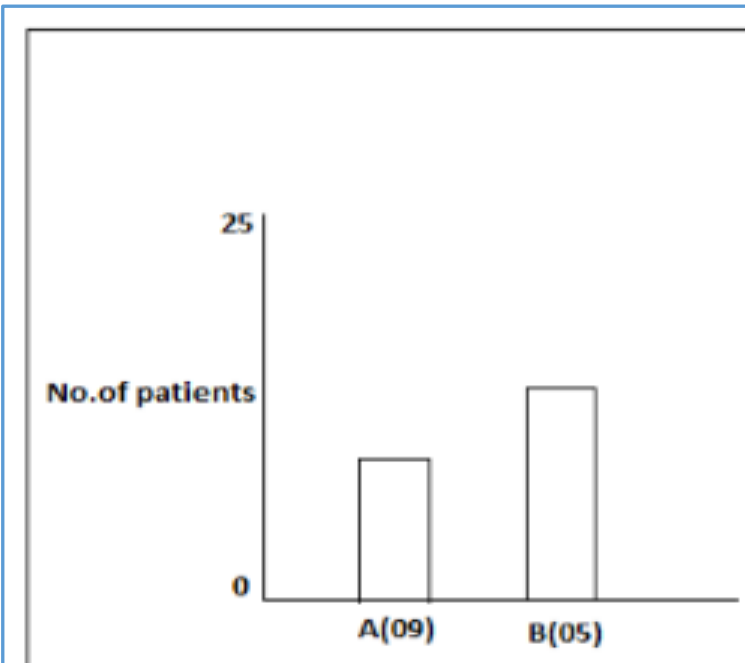

A - defaulted ATT

B - completed ATT

\begin{tabular}{|l|l|l|}
\hline$A$ & $9 / 25$ & $65 \%$ \\
\hline$B$ & $5 / 25 \%$ & $20 \%$ \\
\hline
\end{tabular}

In our study, of the patients with past history of PT only $20 \%$ completed ATT 
4. Time of Reporting

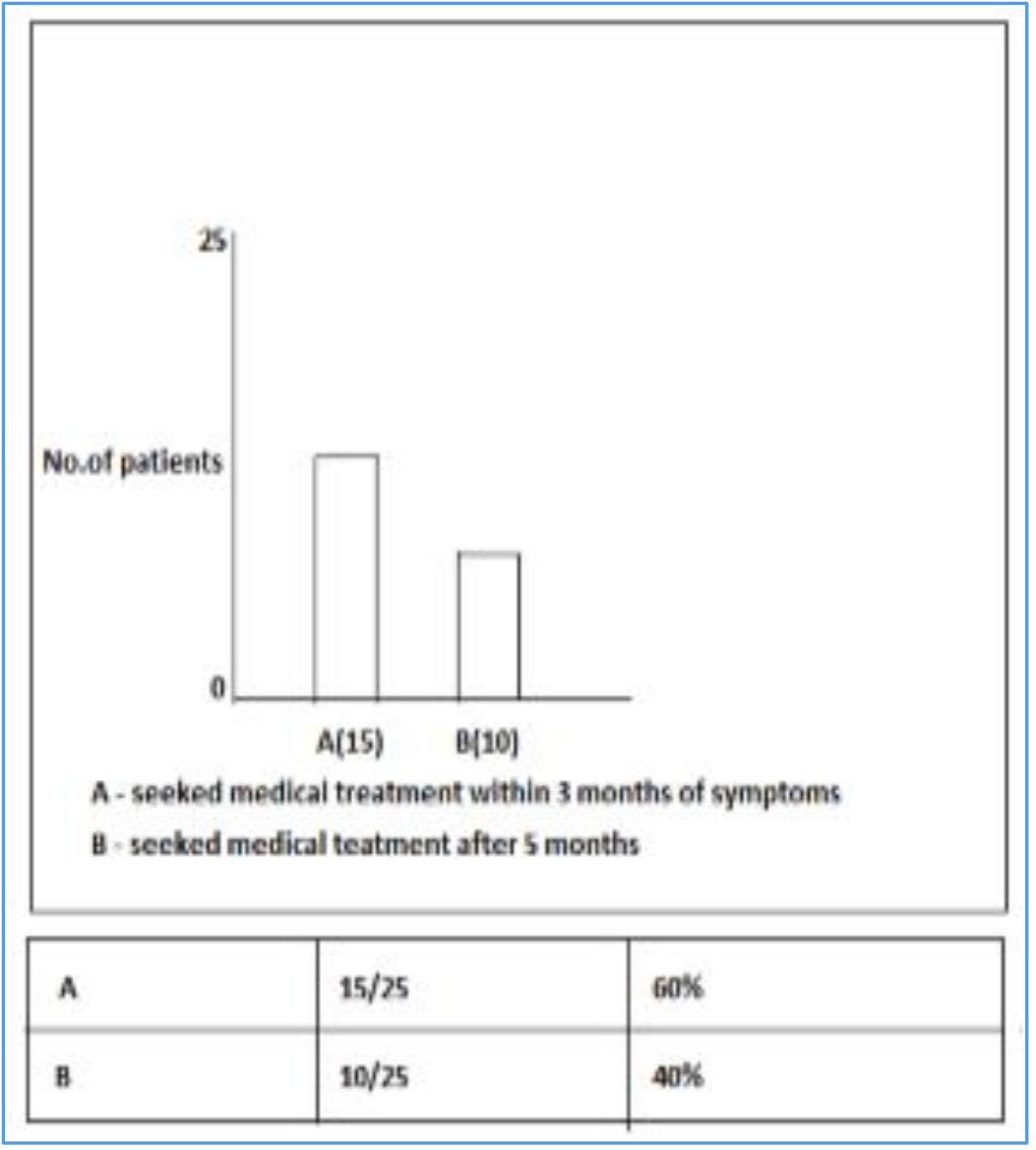

$60 \%$ of patients presented to hospital with in three months of symptoms.

\section{GUTB with Retro Positivity}

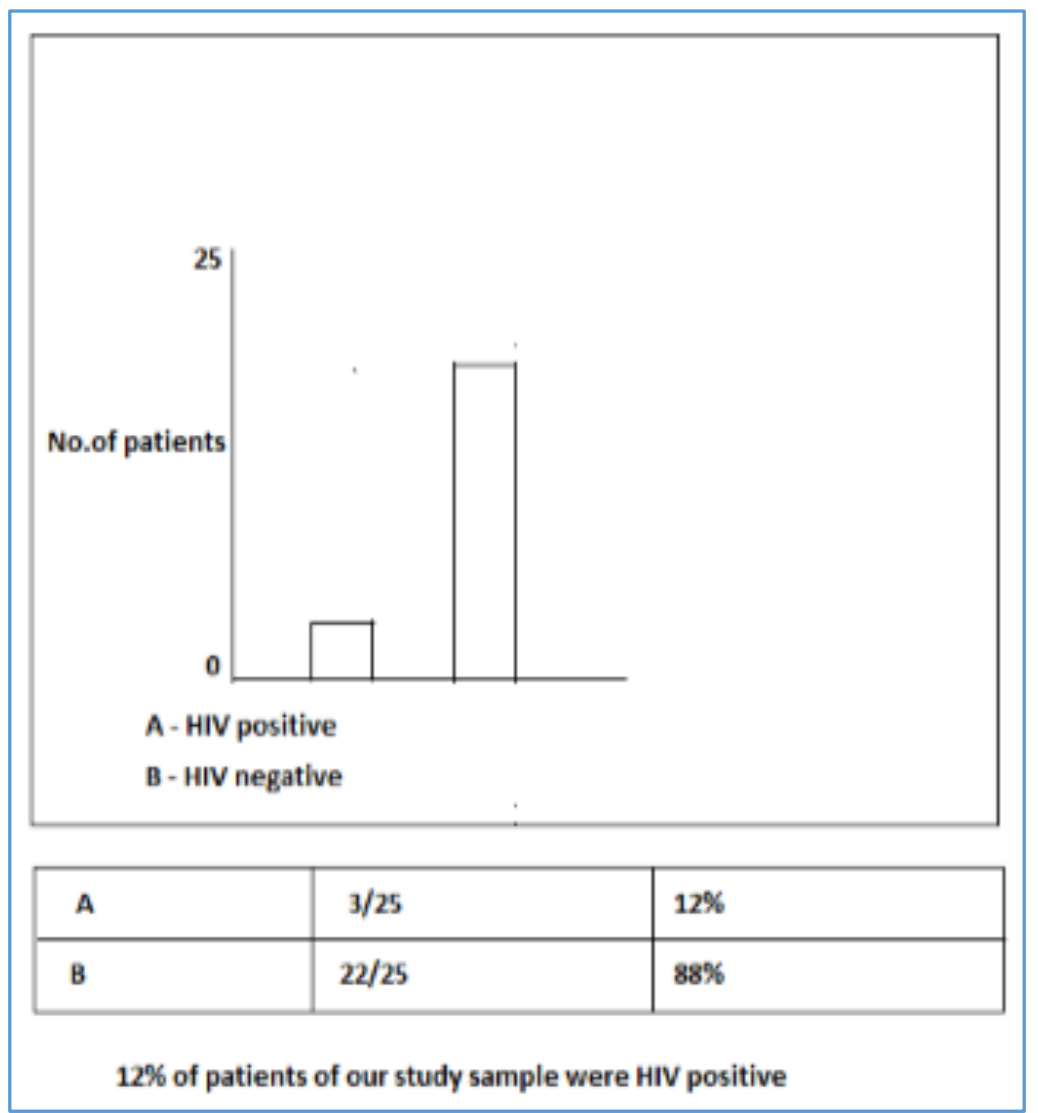




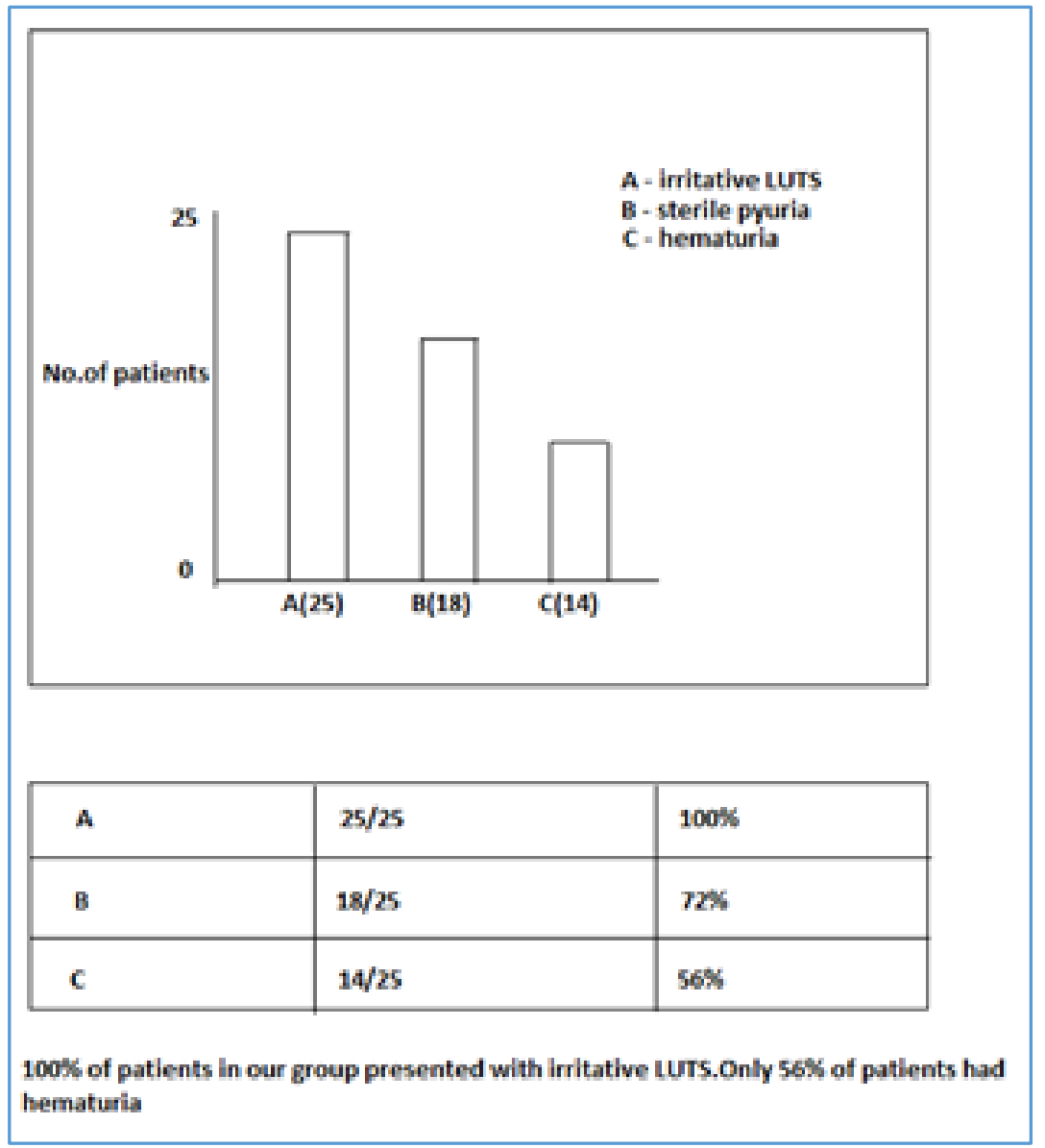

\section{Symptoms of GUTB}

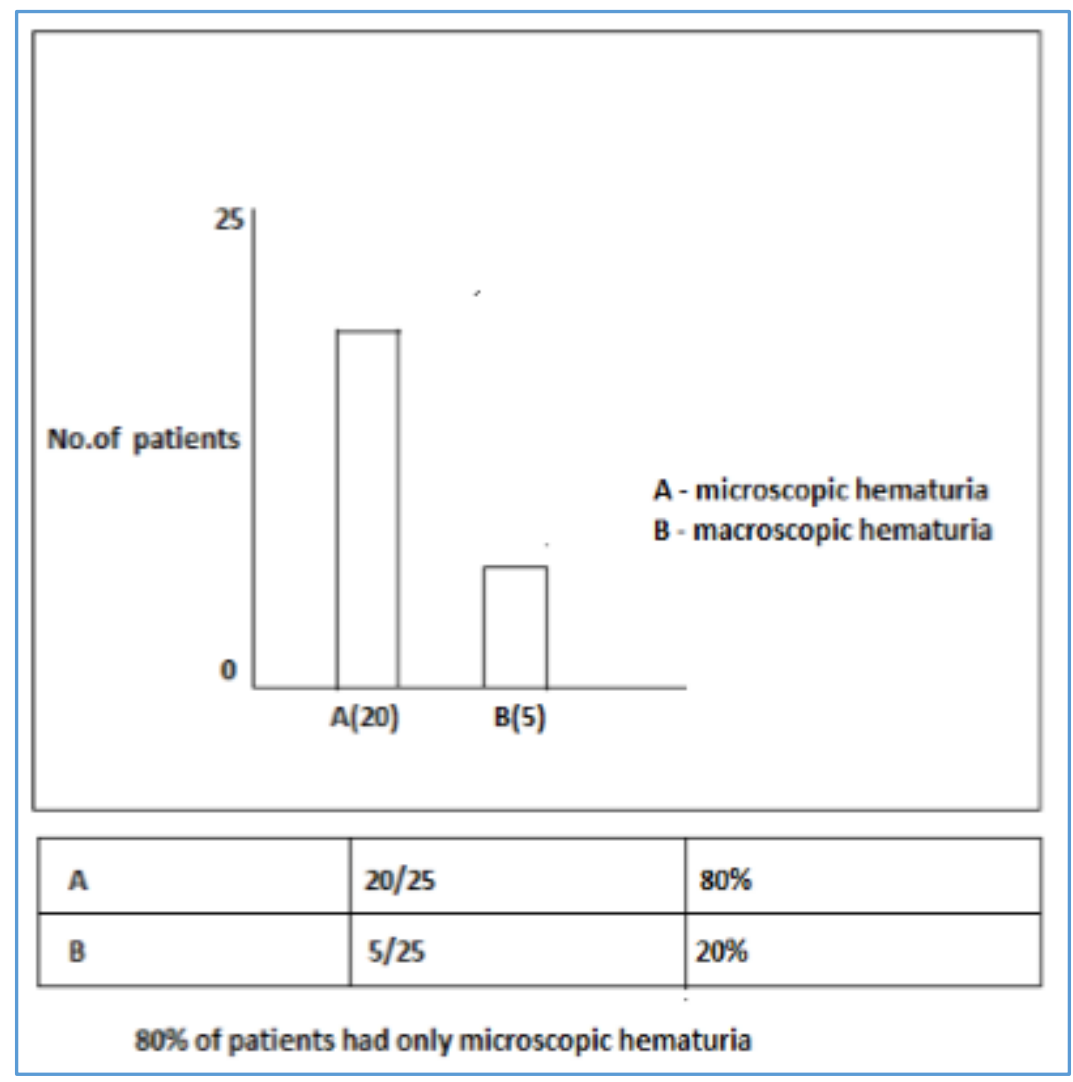


8. Symptoms of GUTB

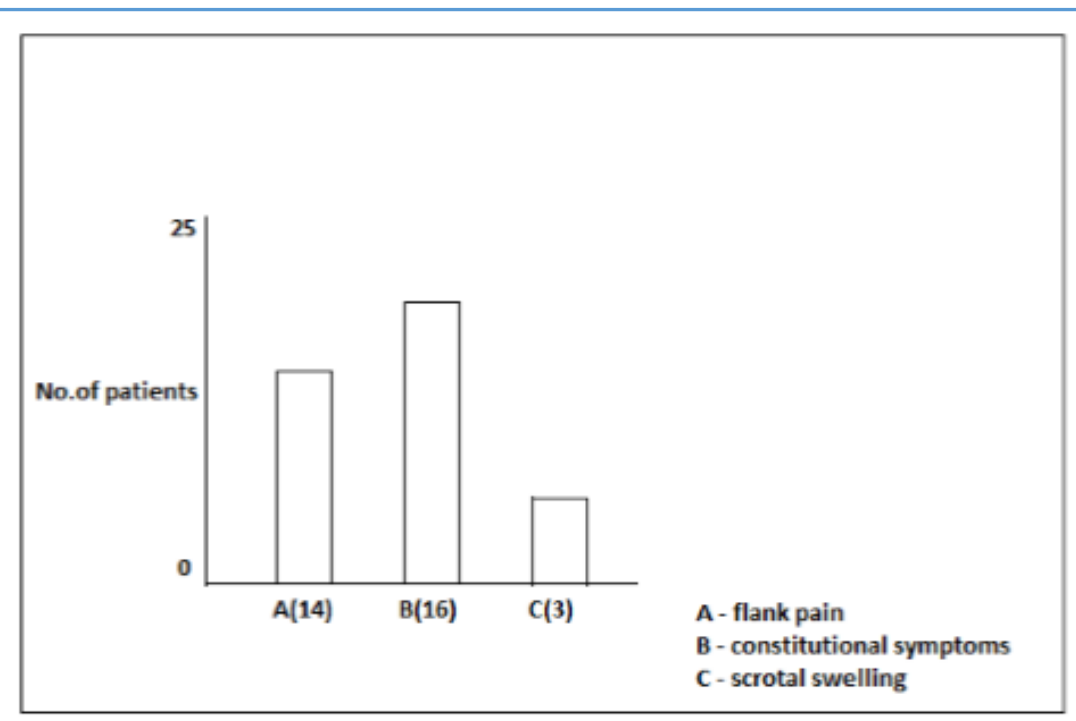

\begin{tabular}{|l|l|l|}
\hline A & $14 / 25$ & $56 \%$ \\
\hline B & $16 / 25$ & $62 \%$ \\
\hline C & $3 / 25$ & $15 \%$ \\
\hline
\end{tabular}

$62 \%$ of patients had constitutional symptoms like low grade fever, loss of weight and appitite

\section{9. $\quad$ RFT in GUTB}

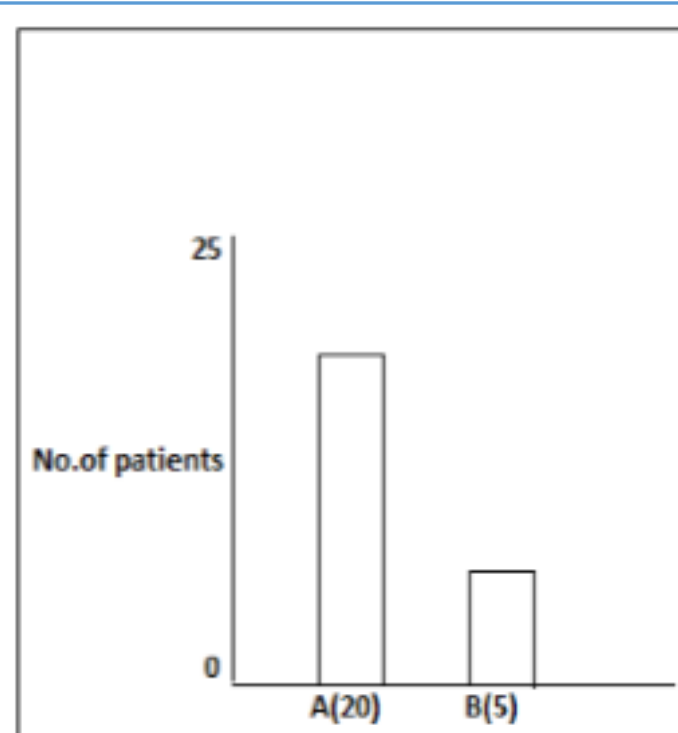

A- normal renal function rest

B - impaired renal function test

\begin{tabular}{|l|l|l|}
\hline A & $20 / 25$ & $80 \%$ \\
\hline B & $5 / 25$ & $20 \%$ \\
\hline
\end{tabular}

$\mathbf{8 0 \%}$ of our patients had normal renal function 
10. ESR in GUTB

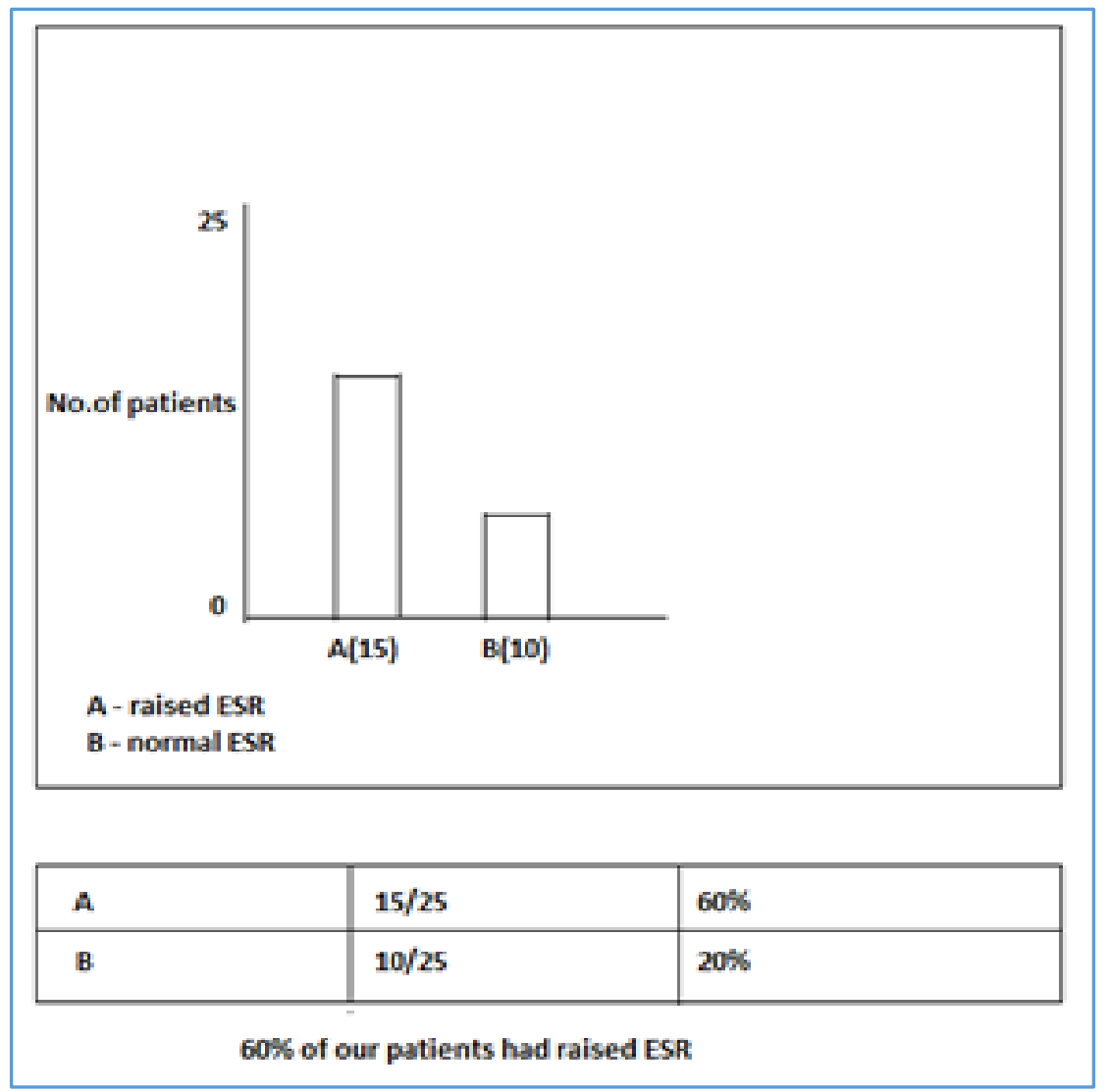

11. IVU Findings

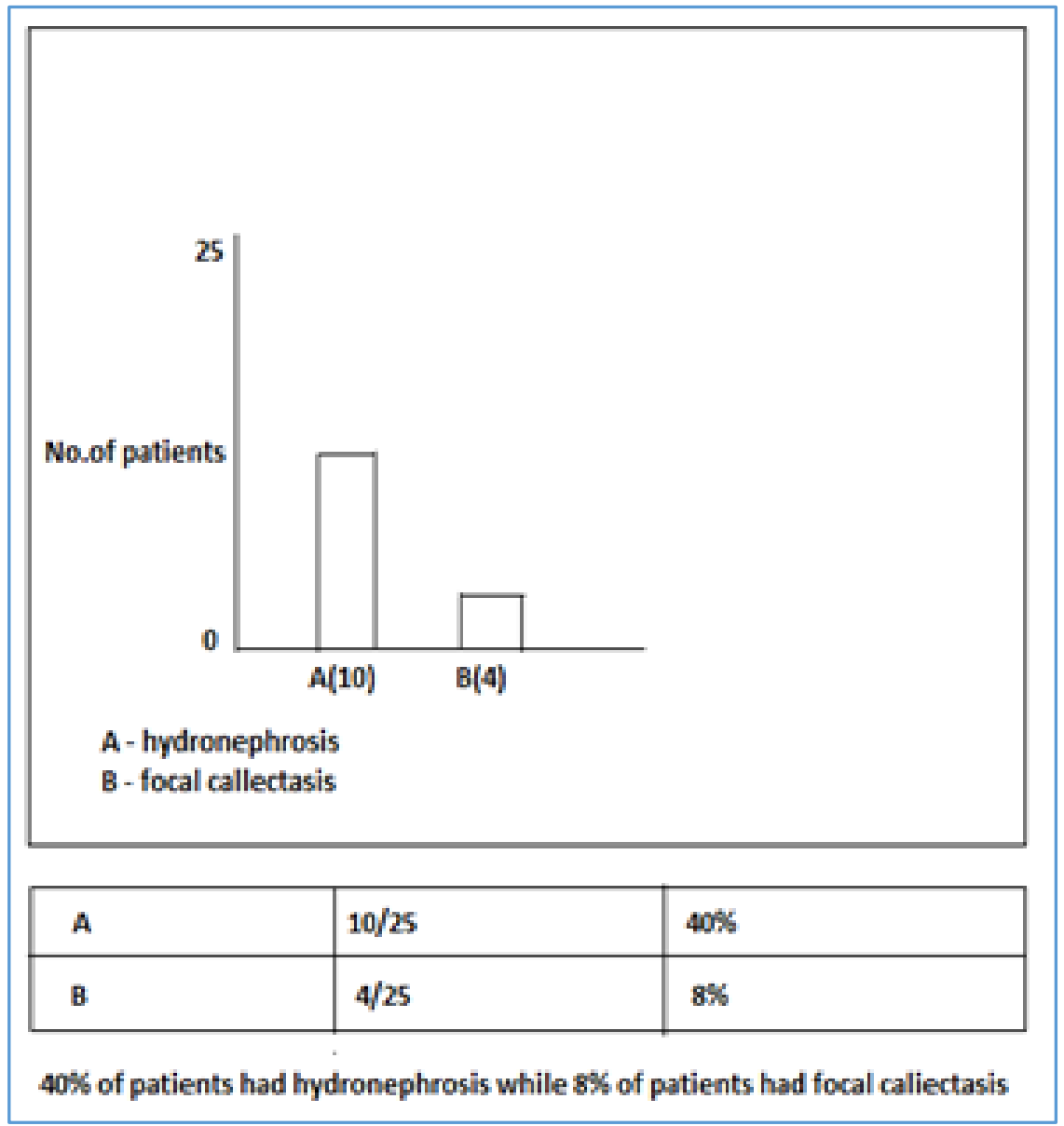




\section{Findings in IVU}

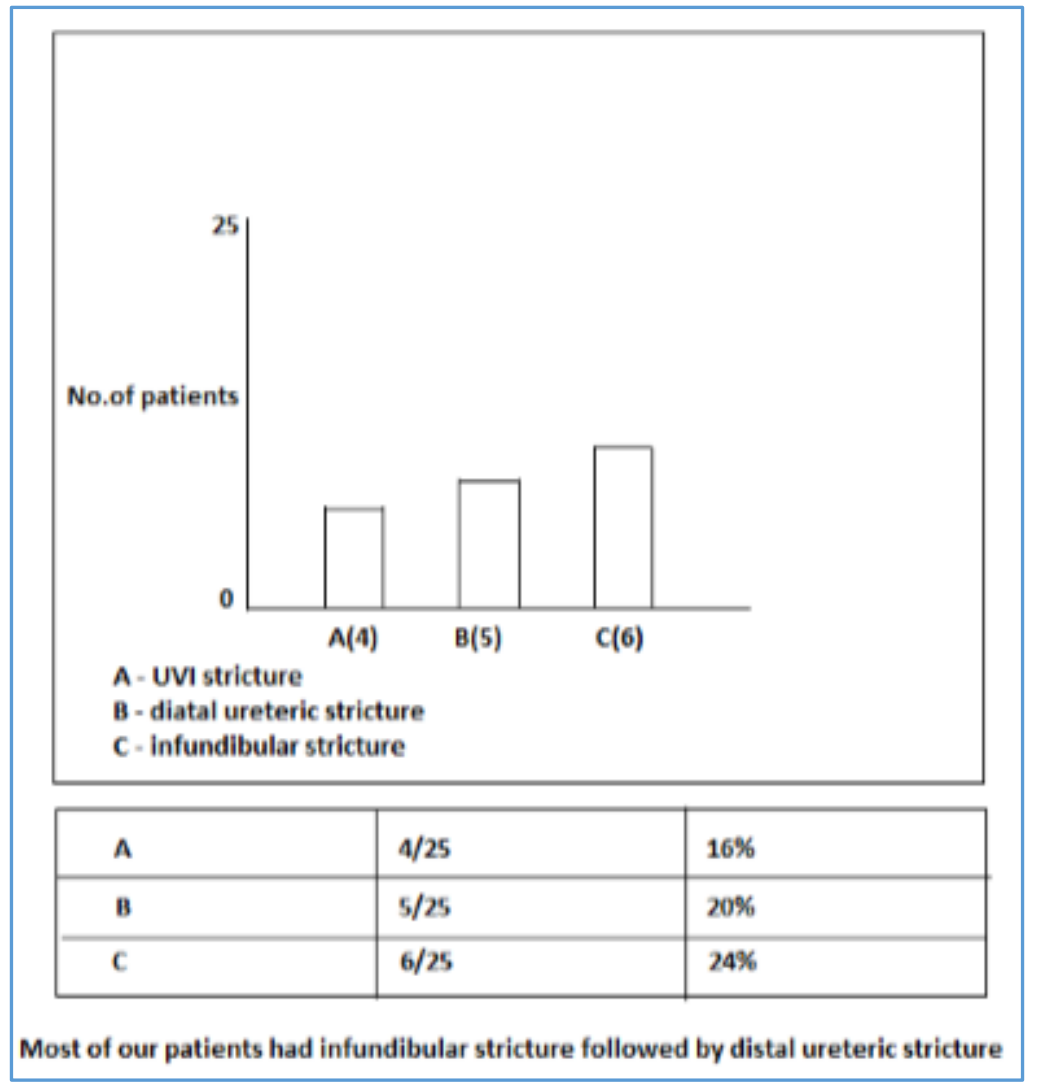

14. Findings in IVU

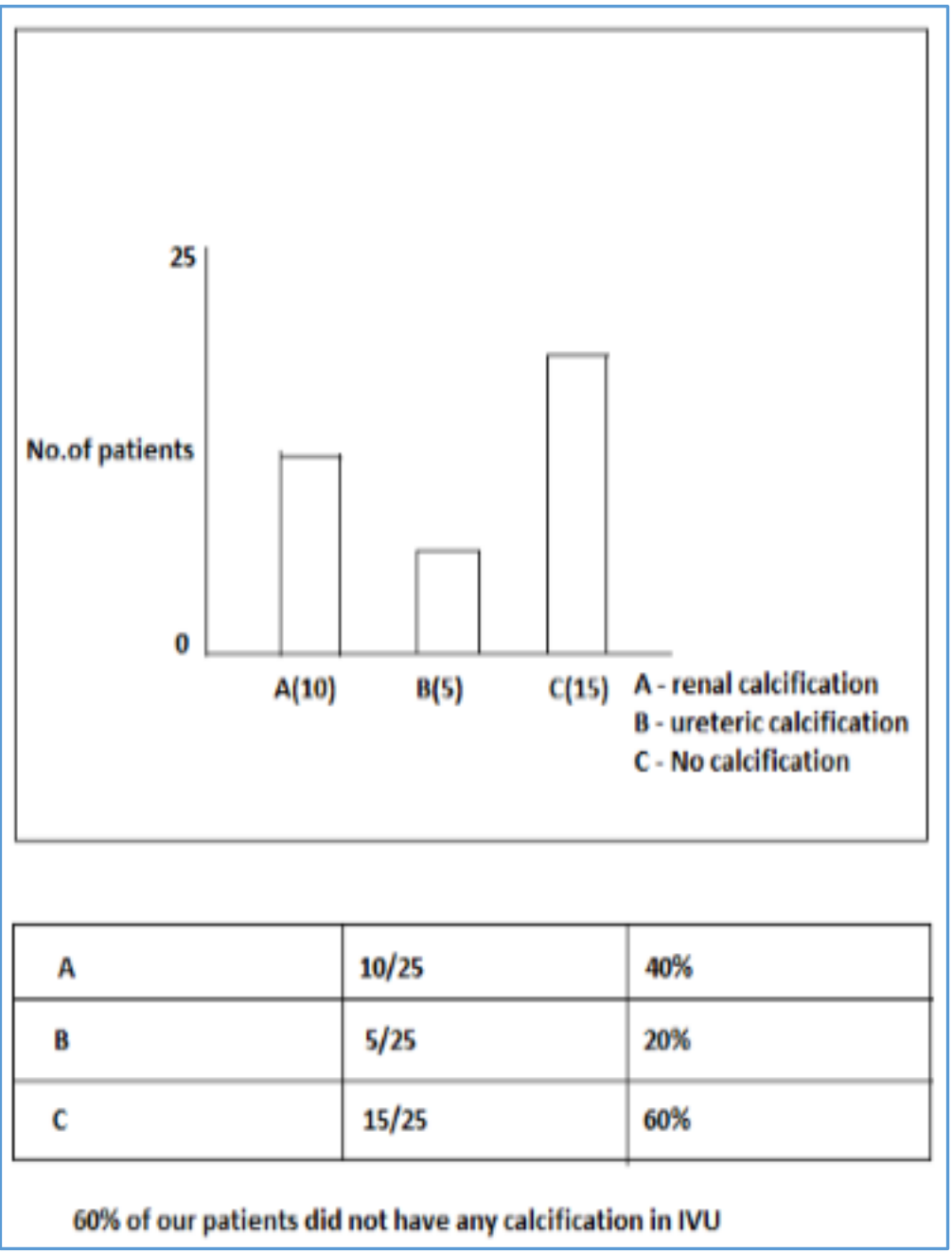




\section{Constitutional Symptoms}

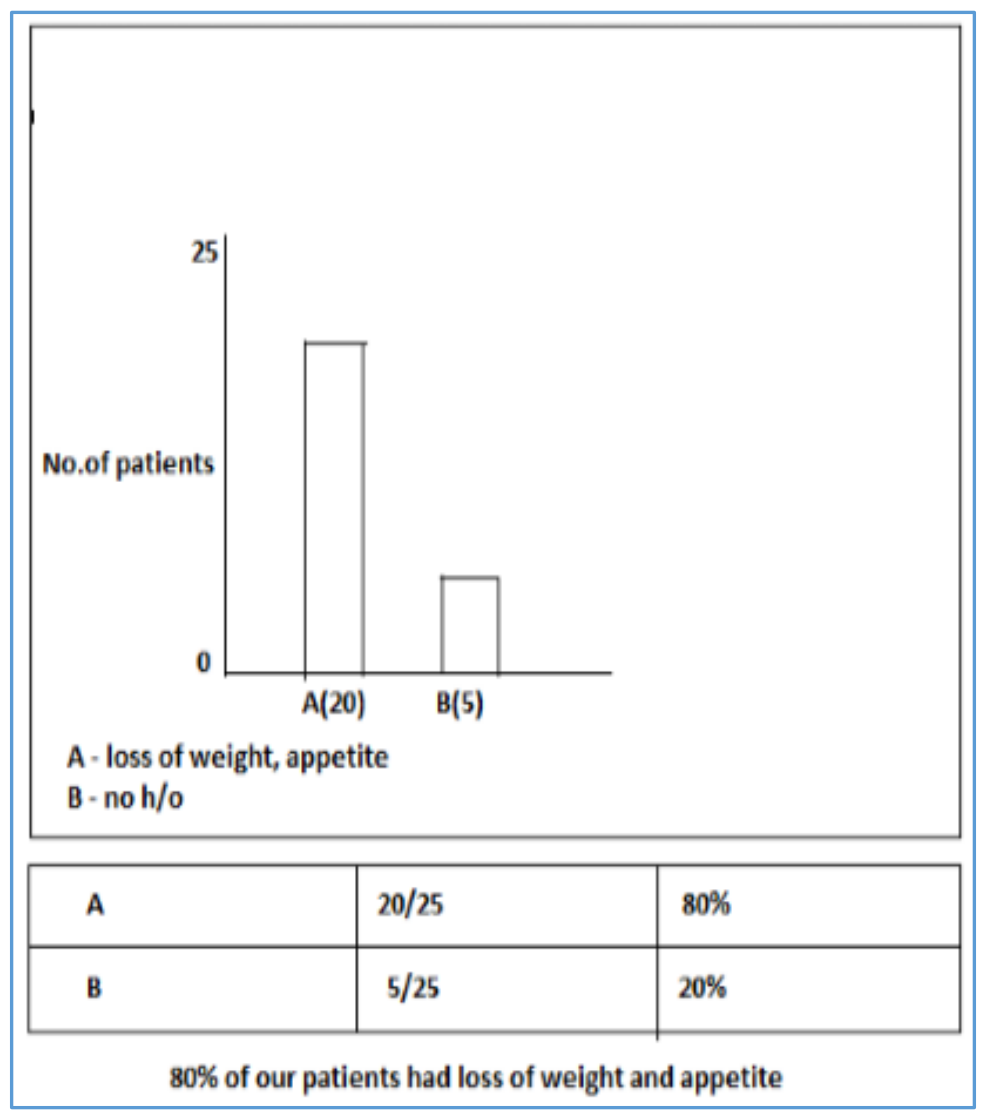

16. Positivity of Investigation

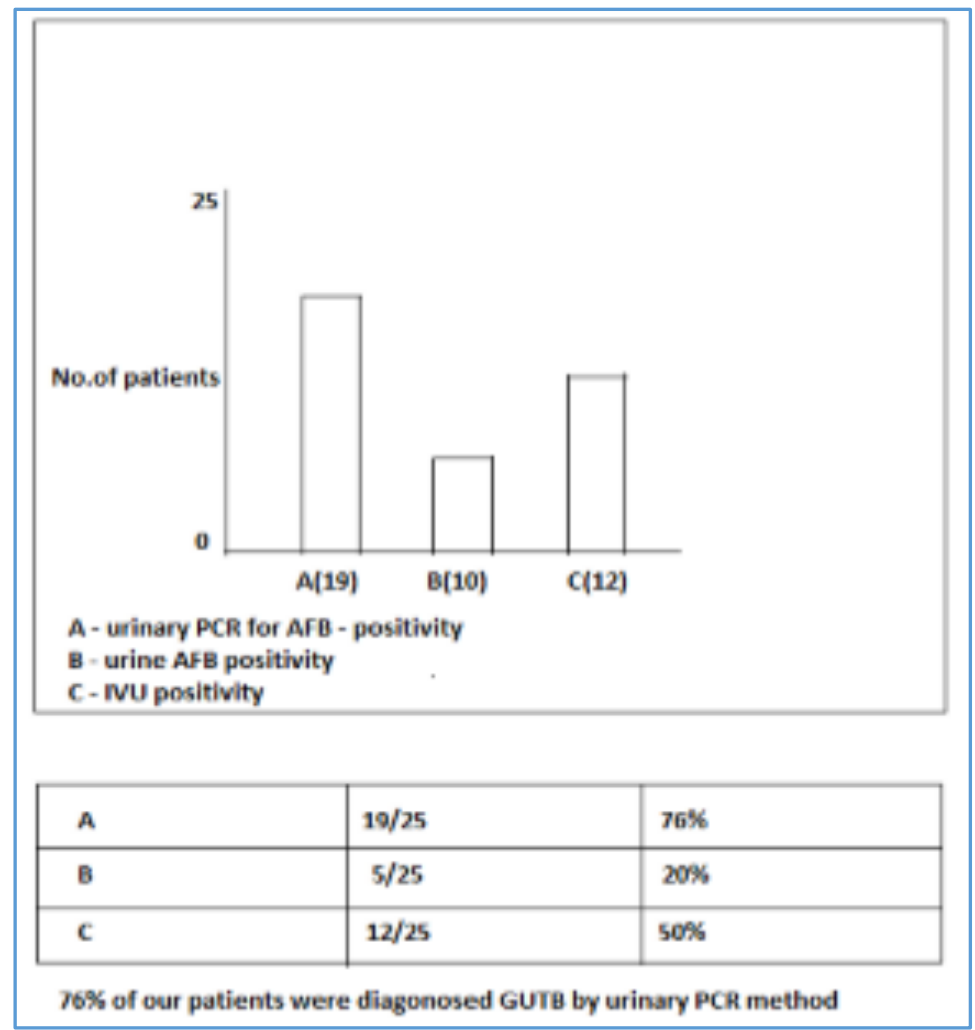

Result and Analysis

Sample Size-25.

Total number of Males- 18.

Total number of Females- 7. 


\section{Most Common Age Group}

- 30 to 40 years.

- 40 to 45 years.

\section{Symptoms/Variables}

- Irritative LUTS- 25.

- $\quad$ Sterile pyuria- 18.

- Hematuria- 14.

- Flank pain- 14.

- Constitutional symptoms-16.

- Scrotal swelling-3.

- Sinus/fistula-Nil.

\section{No. of Patients Subjected to following Investigations}

- Urine AFB- 25.

- Urine PCR-25.

- IVU-25.

\section{RESULTS}

1. Number of patients diagnosed of GUTB from this investigation- 19.

2. No. of patient with past history of P- 12 .

3. No. of patient with active PT- NIL.

4. No. of urinary AFB positive- 10/25.

5. No. of urine PCR positive- $19 / 25$.

6. No. of IVU positive- $12 / 25$.

\begin{tabular}{|c|c|c|c|}
\hline \multicolumn{4}{|c|}{ 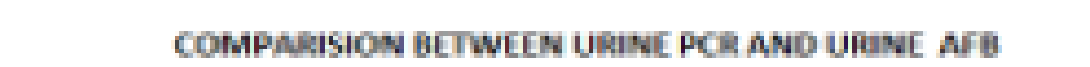 } \\
\hline Dilgonostic tochniqua & \multicolumn{2}{|c|}{ Urine FCR: } & \\
\hline Lrine AFB & Pocithe & Negative & Total \\
\hline Powithe & 10 & 0 & 10 \\
\hline Negaliue & 9 & 6 & $15=$ \\
\hline Total & 19 & 6 & 25 \\
\hline
\end{tabular}

Sensitivity- $52.6 \%$

Specificity- $100 \%$

PPV- $100 \%$

NPV- $66.7 \%$

False negative $\%-47.4 \%$

False positive $\%-0 \%$

Accuracy- $64 \%$ 


\begin{tabular}{|c|c|c|c|}
\hline \multicolumn{4}{|c|}{ COMPARISON BETWEEN URINE PCR AND NU } \\
\hline \multirow{2}{*}{$\begin{array}{l}\text { Diagnostic techniqe } \\
\text { Urine AFB }\end{array}$} & \multicolumn{2}{|c|}{ Urine PCR } & \multirow[b]{2}{*}{ Total } \\
\hline & Positive & Negative & \\
\hline Positive & 12 & 0 & \\
\hline Negative & 7 & 6 & \\
\hline Total & 19 & 6 & 25 \\
\hline
\end{tabular}

Sensitivity- $63.2 \%$

Specificity- $100 \%$

PPV- $100 \%$

NPV- $42.6 \%$

False negative $\%-36.8 \%$

False positive $\%$ - $0 \%$

Accuracy- $72 \%$

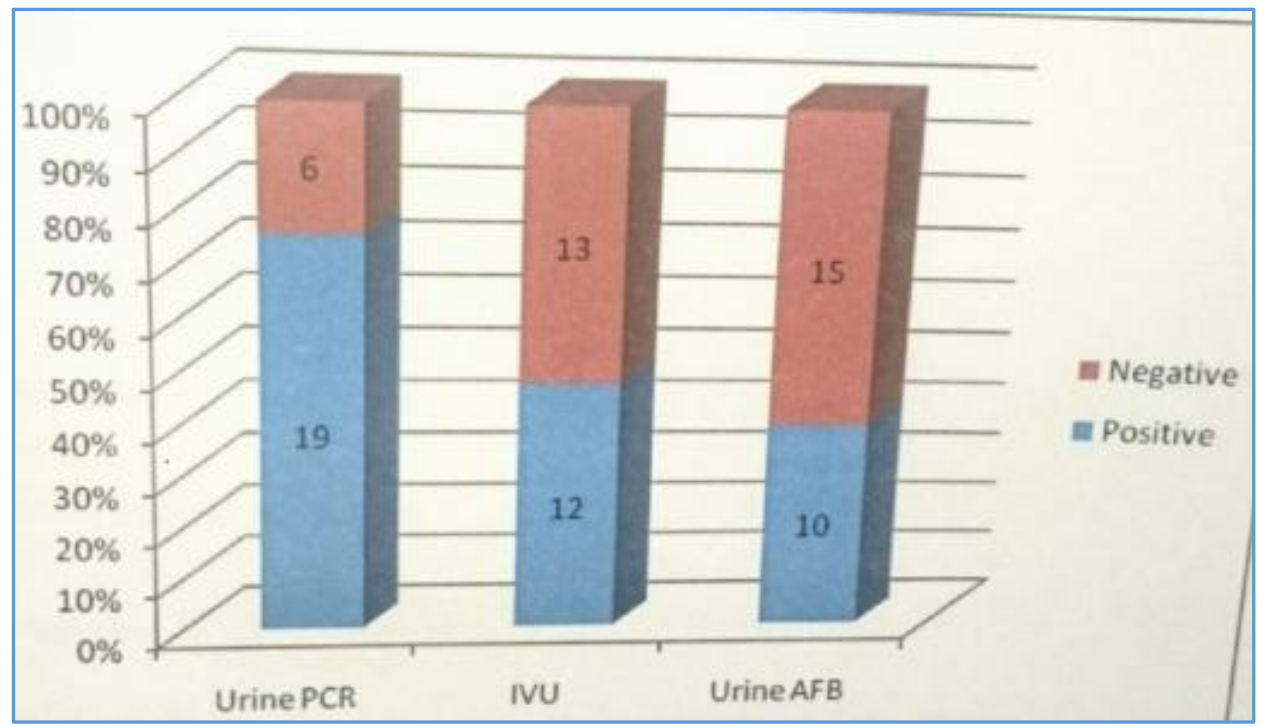

\section{DISCUSSION}

Two important process involved in diagnosing GUTB-

1. High index of suspicion of GUTB.

2. Demonstration of tubercle bacilli in urine sample.

Detection of AFB in urine is usually done by Ziehl Neelson staining method. It is not reliable as culture and sensitivity to make diagnosis of GUTB because of cross contamination with M. Smegmatis. 3-5 consecutive early morning whole urine is must for diagnosing. If at all urine AFB should be positive the sample should contain atleast 10000 bacteria per ml to give a slide positivity. Due to the fact that GUTB is a paucibacillary condition. This is more prone for false negative results. PCR is based on nucleic acid replication technique. Mycobacterial DNA in urine sample is sufficient for diagnosing GUTB. PCR detection limit of mycobacterial DNA is above 5-10 FG, equivalent to 3-5 mycobacteria.

The following PCR tests are available with excellent quality and result-

1. Roche Amplicore MTB PCR test.

2. Genus-specific 16 Sr RNA PCR test.

3. Amplified mycobacterium TB Direct Detection test (AMDT).
4. Species-specific IS6110 PCR.

Although new radiological investigation are in use extensively, IVU Still remains one of the preferred investigation in diagnosis of GUTB. The sensitivity of urine AFB varies from $30-60 \%$ based on single or multiple specimen. The sensitivity of urinary PCR ranges from $88-92 \%$. The sensitivity of IVU varies from $82-85 \%$.

In our study the disease is most commonly seen in male, about $76 \%$ mostly in sexually active period of life (20-40 yrs.$80 \%)$

The variable significant results are, about $56 \%$ of patients had past history of PT, of which only $36 \%$ had completed ATT. $60 \%$ of patients attended hospital within 3 months of symptoms. $12 \%$ of patients were positive for retro virus. $80 \%$ of patients had normal renal functions. $60 \%$ had raised ESR. $72 \%$ of patients had sterile pyuria. $100 \%$ of patient had irritative LUTS. About $56 \%$ of patients had hematuria of which $80 \%$ was microscopic hematuria. Only $56 \%$ had flank pain and $15 \%$ had scrotal mass. In IVU only $40 \%$ of patient had renal and ureteral calcification while $60 \%$ did not have any.

The various finding of GUTB are also plotted in the bar diagram, the most common finding being VUJ narrowing (16\%), distal ureteric stricture (20\%) 
And infundibular narrowing (24\%). in our study urinary PCR was compared with urine AFB and IVU findings.

In a study conducted by National Medical Centre of the Mexican Health Institute, they have concluded that the sensitivity of PCR varies between $88 \%$ to $92.2 \%$ with a specificity of $78.7 \%(5)$

In our study urinary PCR was positive in $76 \%$ of patient while IVU was positive in $50 \%$ of patient and urine AFB was positive in only $20 \%$ of patients, which is comparable to a study conducted at AIIMS, New Delhi as mentioned below-

In another study conducted by department of urology and microbiology at AIIMS, New Delhi the sensitivity of urinary PCR ranges from $70.95 \%$ to $85 \%$ whereas sensitivity of urine AFB was about $22.40 \%$, sensitivity of IVU range from 70 to 80 $\%$

\section{Comparing Urinary AFB with Urinary PCR}

1. In our study the sensitivity of urinary PCR detecting GUTB varied between-

2. 75 to $80 \%$, when comparing with urine AFB. The sensitivity of urine AFB was found to be $52.6 \%$ and specificity of $100 \%$.

3. The positivity prediction (PPV) of urine AFB was $100 \%$

4. The negative predictive value being $66.7 \%$

5. False positive was $0 \%$ false negativity $47.4 \%$

6. The accuracy of detecting GUTB by urine AFB method is about $64 \%$

\section{Comparing IVU with Urinary PCR}

In our study all 25 patients underwent IVU and results were compared as follows-

1. $50 \%$ of patients showed features of GUTB at IVU.

2. The sensitivity of IVU when compared with urine PCR for diagnosing GUTB is about $63.2 \%(+/-5 \%)$

3. The sensitivity being $100 \%$. The positive predicted value (PPV) of IVU is $100 \%$. The negative prediction value (NPV) is $46.2 \%$ The false positive is $0 \%$, false negative is $36.8 \%$. The accuracy of IVU in detecting GUTB was about $72 \%$

\section{CONCLUSION}

In developing countries like India, Tuberculosis is an important public health problem. So, the detection and management of GUTB is important. Timely and early diagnosis will prevent late complications of GUTB like TB pyonephrosis, nonfunctioning kidney and thimble bladder. Since about 8 $15 \%$ of patients with history of PT are prone to develop GUTB it is essential to have rapid diagnosis. PCR is one of the best tools for avoiding delay in diagnosis and treatment since results are available in 4-6 hrs. Whereas culture takes 6-8 weeks of time.

A controlled PCR can help in either excluding or confirming diagnosis of GUTB. Since GUTB is a pauci-bacillary condition, PCR has a prominent role in diagnosis.

The limit of detection of MTB by urinary PCR ranges between 1- 10 bacteria. Moreover, no crossover reaction occurs with other mycobacteria. The false negativity in urinary PCR can be decreased by-

1. Removing PCR inhibitors.

2. Concentrating sample before analysis

3. Testing multiple specimen of same patient.

4. Testing quality specimen.

False positivity in PCR may be due to contamination by amplicons (MTB complex bacteria or DNA) and dead bacteria. The drawbacks of urinary PCR are need for experienced staff, cost, and small no. of samples being done in both private and Government sectors.

Our study concludes that of the three investigations we compared (Urine PCR for MTB, Urine for AFB, IVU) Urine PCR for MTB is the most sensitive indicator in diagnosing GUTB as it gives a rapid, sensitive and specific results.

\section{REFERENCES}

[1] Adult urology, comparison between IVU, bladder biopsy, urine AFB, department of urology \& microbiology, AIIMS, New Delhi.

[2] Majunath N, Shankar P, Rajan L, et al. Evaluation of PCR for the diagnosis of tuberculosis. Tubercle 1991;72(1):21-7.

[3] Antonio D, Gow JG. Renal calcification in genito-urinary tuberculosis: a clinical study. Int Urol Nephrol 1975;7(4):289-95.

[4] Balasubramanian R, Ramachandran R. Management of non-pulmonary forms of tuberculosis: review of TRC studies over two decades. Indian Journal of Pediatrics 2000;67(Suppl 2):S34-S40.

[5] Gow JG. Genitourinary tuberculosis. In: Walsh PC, Retik AB, Starry TA, et al. eds. Campbell's Urology. $6^{\text {th }}$ edn. Philadelphia: Saunders 1992: p. 919-51. 